\title{
Modified Non-Invasive Computational Methods of HIV Drug Com- binations for Treatment of Coronavirus Disease-19 (COVID-19)
}

\author{
Tamer Ezzat Youssef ${ }^{1,2^{*}}$ and Youssef Tamer Moustafa ${ }^{3}$ \\ ${ }^{1}$ Department of Chemistry, Imam Abdulrahman Bin Faisal University, Saudi Arabia \\ ${ }^{2}$ Basic and Applied Scientific Research Center, Imam Abdulrahman Bin Faisal University, Saudi Arabia \\ ${ }^{3}$ School of Professional and Continuing Education, Universiti Teknologi Malaysia, Malaysia
}

*Corresponding author: Tamer Ezzat Youssef, Department of Chemistry, College of Science, Imam Abdulrahman Bin Faisal University, P.O. Box 1982, Dammam 31441, Saudi Arabia, Tel: +966538952007

\begin{abstract}
As of 18 March 2020, more than 191127 cases of confirmed COVID-19 have been documented globally with over 7807 deaths. The impact of COVID-19 on patients with HIV have common presentations like non-HIV patients include fever, dry cough, difficulty of breath. Parallel evidence indicates that the risk of disease increases with critically more than 66 years age, including chronic lung disease. It is very difficult to use drugs on the market. We apply drug design computer techniques to find the expected drug for COVID-19 after knowing the repurposing the detailed of 3D-structures of its key proteins. Several known drugs act as strong inhibitors of COVID-19 protease, including: Abacavir, Lamivudine and Zidovudine. The combination of the analyzed spectra of the antiviral drugs: Abacavir, Lamivudine and Zidovudine help to give an additional information about the investigated set of complex drugs.
\end{abstract}

\section{Keywords}

Coronavirus, COVID-19, HIV drug combination, Trizivir

\section{Introduction}

As of 18 March 2020, more than 191127 cases of confirmed COVID-19 have been documented globally with over 7807 deaths [1].

We reported previously a computational modeling drug design for a category of HIV drugs called non-nucleoside reverse transcriptase inhibitor (NNRTI), nucleoside reverse transcriptase inhibitors (NRTIs) and protease inhibitors (PIs), respectively [2,3].

Following these publications, we published other ar- ticles describe the antitumor activity of a series of photosensitizers tested for several cancer cell lines, and in vivo experiments. We received positive feedback about our research [4-6].

Patients with COVID-19 and HIV are more susceptible to infection due to their Immunodeficiency status. For this reason, all researchers who interest with health care should understand the situation of the disease and find the selective drug to avoid the spread of the disease.

\section{Results}

In this work, we applied multiscale modified non-invasive computational modeling techniques to discover drugs that may be used for repurposing the target COVID-19 protease.

We use drug combinations of three neutral models of Nucleoside/Nucleotide Reverse Transcriptase Inhibitors (NRTIs) Anti-Viral drugs: Abacavir, Lamivudine and Zidovudine (sold under the brand name Trizivir) [7] in comparison with another drug combination as described in Table $1[8,9]$.

Trizivir is used widely for controlling Human Acquired Immunodeficiency Syndrome. In order to extract the reliable information. We subject these data to the procedure of the optimal linear smoothing (POLS), in addition to 3-dimensional Multidimensional Scaling (MDS) methods [3]. Due to the importance of these three drugs for the medical treatment, we

Citation: Youssef TE, Moustafa YT (2020) Modified Non-Invasive Computational Methods of HIV Drug Combinations for Treatment of Coronavirus Disease-19 (COVID-19). Int J Virol AIDS 7:061. doi. org/10.23937/2469-567X/1510061

Accepted: April 09, 2020: Published: April 11, 2020

Copyright: (C) 2020 Youssef TE, et al. This is an open-access article distributed under the terms of the Creative Commons Attribution License, which permits unrestricted use, distribution, and reproduction in any medium, provided the original author and source are credited. 
Table 1: In vitro/in vivo efficacy of the HIV drugs selected for COVID-19.

\begin{tabular}{|l|l|l|l|l|}
\hline Drug & In vitro activity & In vivo activity (animal models) & Clinical studies \\
\hline & SARS-CoV-1 MERS-CoV & SARS-CoV-1 & MERS-CoV & \\
\hline $\begin{array}{l}\text { Lopinavir/ritonavir } \\
\text { (Kaletra); }\end{array}$ & $+/-$ & - & Not studied $+/-$ & Weak efficacy for \\
Used in HIV infection & {$[8]$} & {$[9]$} & & SARS-CoV-1 [8] \\
\hline $\begin{array}{l}\text { Abacavir/Lamivudine/ } \\
\text { Zidovudine } \\
\text { (Trizivir) }\end{array}$ & Not studied & Not studied & Negative results for MERS-CoV [9] \\
\hline \begin{tabular}{l} 
Used in HIV infection \\
\hline
\end{tabular} & & & Ongoing for \\
COVID-19 \\
[Actual work]
\end{tabular}<smiles>Nc1nc(NC2CC2)c2ncn(C3C=CC(CO)C3)c2n1</smiles>

Abacavir<smiles>Nc1ccn([C@@H]2CS[C@H]3CO[C@H]2O3)c(=O)n1</smiles>

Lamivudine<smiles>Cc1cn(C2CC(N)C(CO)O2)c(=O)[nH]c1=O</smiles>

Zidovudine

Figure 1: 2D-Structures of neutral expected antivirals repurposed drugs.

compare the cosine correlation through a $3 \times 3$ matrix of comparison of all drugs provide visualized information of the three drugs. Figure 1 2D-Structures of neutral expected antivirals repurposed drugs.

Combinations of Abacavir, Lamivudine and Zidovudine with these direct-acting antivirals could reduce viral replication, and the aberrant host inflammatory response and viral infectivity.

This work demonstrates that the use of an Al-driven analyzed data can facilitate rapid drug development, compared to the experimental methods, computer-modelling drug approaches are efficient in providing possible drugs for epidemic disease like COVID-19.

\section{Conclusion}

In this study, we use the crystal structure of COVID-19 protease. Abacavir, Lamivudine and Zidovudine used as model for neutral antiviral drugs, may identified to have inhibitory activities against COVID-19 protease. Our computational study can facilitate us to design novel inhibitors targeting COVID-19.

\section{Conflict of Interest}

The authors declare that there is no conflict of interest.

\section{Funding}

There was no funding for this research.

\section{References}

1. World Health Organization Situation Report-58, Coronavi- rus disease 2019 (COVID-19) (2020) Data as reported by national authorities by 00:00 CET 18 March 2020.

2. Machado JAT, Baleanu D, AL-Zahrani AA, AL-Hamed $Y$, Zahid AH, et al. (2014) On similarities in Infrared spectra of complex drugs. Romanian reports in Physics 66: 382-393.

3. Nigmatullin RR, Baleanu D, AL-Zahrani AA, AL-Hamed Y, Zahid A H, et al. (2013) Spectral analysis of HIV drugs for acquired immunodeficiency syndrome within modified non-invasive methods. Revista de Chimie 64: 987-993.

4. Abdel Fadeel D, Al-Toukhyb GM, Elsharif AM, Al-Jameel SS, Mohamed $\mathrm{HH}$, et al. (2018) Improved photodynamic efficacy of thiophenyl sulfonated zinc phthalocynine loaded in lipid nano-carriers as new formulation for hepatocellular carcinoma cancer cells. Photodiagnosis Photodyn Ther 23: 25-31.

5. Al Jameel SS, Youssef TE (2018) Investigations on the antitumor activity of classical trifluoro-substituted zinc phthalocyanines derivatives. World Journal Microbiology and Biotechnology 34: 52.

6. Youssef TE, Y AL-Hamed Y, AL-Sharani S (2014) Antitumor activity of tetra-substituted zinc phthalocyanines containing $4(3 \mathrm{H})$-quinazolinone derivatives. Revista de Chimie (Bucharest) 65: 560-564.

7. Hartmann K, Anita Wooding A, Bergmann M (2015) Efficacy of antiviral drugs against feline immunodeficiency virus. Vet Sci 2: 456-476.

8. Chan JF-W, Yao Y, Yeung M-L, Deng W, Bao L, et al. (2015) Treatment with Lopinavir/Ritonavir or Interferon- $\beta 1 \mathrm{~b}$ Improves Outcome of MERS-CoV Infection in a Nonhuman Primate Model of Common Marmoset. J Infect Dis 212: 1904-1913.

9. Chan JFW, Chan K-H, Kao RYT, To KKW, Zheng B-J, et al. (2013) Broad-spectrum antivirals for the emerging Middle East respiratory syndrome coronavirus. J Infect 67: 606616. 